\title{
Article \\ Edge Metric and Fault-Tolerant Edge Metric Dimension of Hollow Coronoid
}

\author{
Ali N. A. Koam ${ }^{1}\left(\mathbb{D}\right.$, Ali Ahmad ${ }^{2, *} \mathbb{C}$, Muhammad Ibrahim ${ }^{3}\left(\mathbb{D}\right.$ and Muhammad Azeem ${ }^{4}$ \\ 1 Department of Mathematics, College of Science, Jazan University, New Campus, Jazan 45142, Saudi Arabia; \\ akoum@jazanu.edu.sa \\ 2 College of Computer Science and Information Technology, Jazan University, Jazan 45142, Saudi Arabia \\ 3 Centre for Advanced Studies in Pure and Applied Mathematics, Bahauddin Zakariya University Multan, \\ Multan 60800, Pakistan; mibtufail@gmail.com \\ 4 Department of Aerospace Engineering, Faculty of Engineering, Universiti Putra Malaysia, \\ Seri Kembangan 43400, Malaysia; azeemali7009@gmail.com \\ * Correspondence: ahmadsms@gmail.com or aimam@jazanu.edu.sa
}

Citation: Koam, A.N.A.; Ahmad, A.; Ibrahim, M.; Azeem, M. Edge Metric and Fault-Tolerant Edge Metric Dimension of Hollow Coronoid. Mathematics 2021, 9, 1405. https:// doi.org/10.3390/math9121405

Academic Editor: Ismael

González Yero

Received: 15 May 2021

Accepted: 14 June 2021

Published: 17 June 2021

Publisher's Note: MDPI stays neutral with regard to jurisdictional claims in published maps and institutional affiliations.

Copyright: (c) 2021 by the authors. Licensee MDPI, Basel, Switzerland. This article is an open access article distributed under the terms and conditions of the Creative Commons Attribution (CC BY) license (https:// creativecommons.org/licenses/by/ $4.0 /)$.

\begin{abstract}
Geometric arrangements of hexagons into six sides of benzenoids are known as coronoid systems. They are organic chemical structures by definition. Hollow coronoids are divided into two types: primitive and catacondensed coronoids. Polycyclic conjugated hydrocarbon is another name for them. Chemical mathematics piques the curiosity of scientists from a variety of disciplines. Graph theory has always played an important role in making chemical structures intelligible and useful. After converting a chemical structure into a graph, many theoretical and investigative studies on structures can be carried out. Among the different parameters of graph theory, the dimension of edge metric is the most recent, unique, and important parameter. Few proposed vertices are picked in this notion, such as all graph edges have unique locations or identifications. Different (edge) metric-based concept for the structure of hollow coronoid were discussed in this study.
\end{abstract}

Keywords: hollow coronoid; edge metric dimension; edge resolving set; fault-tolerant edge metric dimension

MSC: 05C12; 05C90; 05C05

\section{Introduction}

Molecular graph theory is considered a diversified area of chemistry and mathematics, as it deals with application of mathematics for chemical structures. Mathematicians can debate attributes and offer an optimum solution by studying various chemical structures (networks) and their different shapes in the visualization of graphs (typically made of vertex and edge) [1]. Making a graph or converting a graph from a chemical topological (it can be a network or structure) reveals the topology in the simplest or most understandable way. Various previous research have shown that when a chemical network is transformed to a graph, the atoms become vertex and the lines (bonds) connecting the atoms become edges. Finally, this applied mathematics aids in the resolution of complicated puzzles or offers the tools necessary to comprehend them.

There are a variety of approaches to evaluate and research electrical circuits using graph theory, and graph theoretical parameters may be used in electronics. In 1975, Slater [2,3], presented an effective notion of network visualization known as metric basis or resolving set, in which principle nodes were picked to achieve the whole set of vertices in a unique identity in terms of distance positions. This concept established the groundwork for a slew of graphs and theoretical parameters that have since been used in a variety of electrical, engineering, and chemical areas. The dealing with of the failure of a single principle node and the resolving set provided the way to get a full set of principle nodes to retain their unique position, as specified by [4], and is known as the fault-tolerant resolving 
set. Partition resolving set [5] is created if the entire set of nodes is distributed into different subsets with the constraint of obtaining the positions for each node is unique. The above notions are renowned resolvability parameters in terms of metric that have been researched for many graphs, networks, and structures.

Computational complexity of the notions of resolvability parameters discussed here falls in the range of non-deterministic polynomial-time hardness problems as addressed in these literatures [5-8]. The actuality that this notion has a range of useful favors in our daily practicality motivates researchers. The concept of metric dimension has been applied to a variety of problems, including coastguard loran, sonar, and facility location problems [2], and various studies on combinatorial optimization [9]. Pharmaceutical chemistry being the part as a usage of graph theory, as discussed in [8], robot navigation [10], and the weighing problem of coins [11]. Computer networks [12] are all related to this concept. For a more in-depth look at how resolvability parameters are used [13,14], and [3,8,15-17] can be studied.

Graph metric dimension is used immensely in the chemical field for studying different structures that is evident from these articles. The $V C_{5} C_{7}$ nano-tubes and structure of $\mathrm{H}$ Naphtalenic are studied in [18], sharps bounds are computed for the network of cellulose with respect to distance based graph theoretical parameters in [19], $\alpha$-boron nanotubes derived from two dimensional lattice are studied in [20], and also provide some links for its applications, [21] computed the distance-based metric for the silicate star. Moving towards the edge metric dimension, barycentric subdivision of Cayley graph studied in [22], few work on the convex polytopes structure discussed by $[23,24]$, the wheel graphs related chemical structures are discussed in [25] and a quantitative review between metric its other versions is done in [26], moreover, the seminal work on the edge metric dimension can be found in [27]. The renowned chemical topology of polycyclic aromatic hydrocarbons are discussed in [28], with the conceptualization of resolvability parameters.

Terminologies of graph theory changed from application to application. For example, open circuits and the current sources were labeled as vertices in an electrical circuit, while passive parts along with voltage sources were relabeled by edges. According to [29], edges, called branches or line segments, and the vertices are renamed as simply nodes or principal nodes.

Definition $1([30,31])$. Suppose $\aleph(V(\aleph), E(\aleph))$ is an undirected graph of a chemical structure (network) with $V(\aleph)$ is called as set of principal nodes (vertex set) and $E(\aleph)$ is the set of branches (edge set). The distance between two principal nodes $\zeta_{1}, \zeta_{2} \in V(\aleph)$, denoted as $d\left(\zeta_{1}, \zeta_{2}\right)$ is the minimum count of branches between $\zeta_{1}-\zeta_{2}$ path.

Definition 2 ([2,31]). Suppose $R \subset V(\aleph)$ is the subset of principal nodes set and defined as $R=\left\{\zeta_{1}, \zeta_{2}, \ldots, \zeta_{s}\right\}$, and let a principal node $\zeta \in V(\aleph)$. The identification or locations $I(\zeta \mid R)$ of a principal node $\zeta$ with respect to $R$ is actually a s-ordered distances $\left(d\left(\zeta, \zeta_{1}\right), d\left(\zeta, \zeta_{2}\right), \ldots, d\left(\zeta, \zeta_{s}\right)\right)$. If each principal node from $V(\aleph)$ have unique identification according to the ordered subset $R$, then this subset renamed as a resolving set of network $\aleph$. The minimum numbers of the elements in the subset $R$ is actually the metric dimension of $\aleph$ and it is denoted by the term $\operatorname{dim}(\aleph)$.

Definition 3 ([31,32]). A principal node $\zeta \in V(\aleph)$ and a branch $e=\zeta_{1} \zeta_{2} \in E(\aleph)$, the distance between $\zeta$ and $e$ is defined as $d(e, \zeta)=\min \left\{d\left(\zeta_{1}, \zeta\right), d\left(\zeta_{2}, \zeta\right)\right\}$. Suppose $R_{e} \subset V(\aleph)$ is the subset of principal nodes set and defined as $R_{e}=\left\{\zeta_{1}, \zeta_{2}, \ldots, \zeta_{s}\right\}$, and a branch $e \in E(\aleph)$. The identification $I\left(e \mid R_{e}\right)$ of a branch e with respect to $R_{e}$ is actually a s-tuple distances $\left(d\left(e, \zeta_{1}\right), d\left(e, \zeta_{2}\right), \ldots\right.$, $\left.d\left(e, \zeta_{s}\right)\right)$. If each branch from $E(\aleph)$ have unique identification according to $R_{e}$, then $R_{e}$ is called an edge metric resolving set of network $\aleph$. The minimum count of the elements in $R_{e}$ is called the edge metric dimension of $\aleph$ and it is represented by $\operatorname{dim}_{e}(\aleph)$.

Definition 4 ([33]). An edge metric resolving set $R_{e}$ of a network $\aleph$ is said to be a fault-tolerant edge metric $\left(R_{e, f}\right)$ if for each $\zeta \in R_{e}, R_{e} \backslash \zeta$ is also a edge metric resolving set for $\aleph$. The minimum 
amount of the fault-tolerant edge metric resolving set is known as the fault-tolerant edge metric dimension and described as $\operatorname{dim}_{e, f}(\aleph)$.

Theorem 1 ([33]). Let $\operatorname{dim}_{e}(\aleph), \operatorname{dim}_{e, f}(\aleph)$ are the edge metric and fault-tolerant edge metric dimension of graph $\aleph$, respectively. Then

$$
\operatorname{dim}_{e, f}(\aleph) \geq \operatorname{dim}_{e}(\aleph)+1 .
$$

\section{Construction of Hollow Coronoid $H C\left(C_{1}, C_{2}, C_{3}\right)$}

Due to a probable relationship with benzenoid, [34] coined the word coronoid in 1987. Because coronoid is a benzenoid with a hole in the middle. Coronoid is a type of polyhex system that has its roots in organic chemistry. A hollow coronoid structure is depicted in Figure 1. When the specific values of moving parameters $C_{1}=C_{2}=C_{3}=3$, kekule is a part of hollow coronoid [35]. A pericondensed benzenoids structure which is known as circumcoronene also among the family of hollow coronoids [36]. A hollow coronoid, as depicted in Figure 1, had total 6 facets $C_{1}, C_{2}, C_{3}, C_{4}, C_{5}, C_{6}$. It is rooted from the catacondensed coronoids and also belongs to the family of primitive coronoids [37].

In [38], one can find a new form of hollow coronoid topologies. The authors explored some of the structure's topological features, as well as their relevance. Zigzag-edge coronoid [39] is another name for this structure. The authors talked about several important aspects of hollow coronoid topology. We refer to [40] for the mathematical analysis of coronoid and related structures. The new research effort [41] is for polynomial investigation of hollow coronoid. In this paper, the authors computed several polynomials. The connection between hollow coronoid and polyhex is described in [42]. The authors of this work talked about the mathematical chemistry of coronoid structure. We refer to the lecture notes and books for a better knowledge of the hollow coronoid and its generalizations [35,37].

In this paper, we take a look at a hollow coronoid with $C_{1}=C_{4}, C_{2}=C_{5}, C_{3}=C_{6}$, with total 6 facets, but the three $\left(C_{1}, C_{2}, C_{3}\right)$ sides are symmetric to other three $\left(C_{4}, C_{5}, C_{6}\right)$. This hollow coronoid is referred to as $H C\left(C_{1}, C_{2}, C_{3}\right)$, with $C_{1}, C_{2}, C_{3} \geq 2$. The construction had a total of $8\left(C_{1}+C_{2}+C_{3}-3\right)$ nodes or vertices, in which $4\left(C_{1}+C_{2}+C_{3}-3\right)$ have the same number of vertices as degree two and have the same number of vertices as degree three. The total number of edges is (branches, line segments, or bonds) are $10\left(C_{1}+C_{2}+C_{3}-3\right)$. The hollow coronoid $H C\left(C_{1}, C_{2}, C_{3}\right)$ structure's vertex and edge set are described as follows:

$$
\begin{aligned}
V\left(H C\left(C_{1}, C_{2}, C_{3}\right)\right)= & \left\{a_{\epsilon}, a_{\epsilon}^{\prime}: 1 \leq \epsilon \leq 2 C_{3}-1\right\} \cup\left\{b_{\epsilon}, b_{\epsilon}^{\prime},: 1 \leq \epsilon \leq 2 C_{1}-1\right\} \cup\left\{c_{\epsilon}, c_{\epsilon}^{\prime}: 1 \leq\right. \\
& \left.\epsilon \leq 2 C_{2}-1\right\} \cup\left\{d_{\epsilon}, d_{\epsilon}^{\prime}: 1 \leq \epsilon \leq 2 C_{3}-3\right\} \cup\left\{e_{\epsilon}, e_{\epsilon}^{\prime},: 1 \leq \epsilon \leq 2 C_{1}-3\right\} \cup \\
& \left\{f_{\epsilon}, f_{\epsilon}^{\prime}: 1 \leq \epsilon \leq 2 C_{2}-3\right\}, \\
E\left(H C\left(C_{1}, C_{2}, C_{3}\right)\right)= & \left\{a_{\epsilon} a_{\epsilon+1}, a_{\epsilon}^{\prime} a_{\epsilon+1}^{\prime}: 1 \leq \epsilon \leq 2 C_{3}-2\right\} \cup\left\{b_{\epsilon} b_{\epsilon+1}, b_{\epsilon}^{\prime} b_{\epsilon+1}^{\prime},: 1 \leq \epsilon \leq 2 C_{1}-2\right\} \\
& \cup\left\{c_{\epsilon} c_{\epsilon+1}, c_{\epsilon}^{\prime} c_{\epsilon+1}^{\prime},: 1 \leq \epsilon \leq 2 C_{2}-2\right\} \cup\left\{d_{\epsilon} d_{\epsilon+1}, d_{\epsilon}^{\prime} d_{\epsilon+1}^{\prime},: 1 \leq \epsilon \leq 2 C_{3}-4\right\} \\
& \cup\left\{e_{\epsilon} e_{\epsilon+1}, e_{\epsilon}^{\prime} e_{\epsilon+1}^{\prime},: 1 \leq \epsilon \leq 2 C_{1}-4\right\} \cup\left\{f_{\epsilon} f_{\epsilon+1}, f_{\epsilon}^{\prime} f_{\epsilon+1}^{\prime},: 1 \leq \epsilon \leq 2 C_{2}-4\right\} \\
& \left.\cup\left\{a_{\epsilon+1} d_{\epsilon}, a_{\epsilon+1}^{\prime} d_{\epsilon}^{\prime}: 1 \leq \epsilon \text { odd }\right) \leq 2 C_{3}-3\right\} \cup\left\{b_{\epsilon+1} e_{\epsilon}, b_{\epsilon+1}^{\prime} e_{\epsilon}^{\prime}, 1 \leq \epsilon(\text { odd })\right. \\
& \left.\leq 2 C_{1}-3\right\} \cup\left\{c_{\epsilon+1} f_{\epsilon}, c_{\epsilon+1}^{\prime} f_{\epsilon}^{\prime}: 1 \leq \epsilon(\text { odd }) \leq 2 C_{2}-3\right\} \cup\left\{a_{1} c_{1}, a_{1}^{\prime} c_{1}^{\prime}, a_{2 C_{3}-1} b_{1},\right. \\
& a_{2 C_{3}-1}^{\prime} b_{2 C_{1}-1}, b_{2 C_{1}-1}^{\prime} c_{2 C_{2}-1}^{\prime}, b_{1}^{\prime} c_{2 C_{2}-1}, d_{1} f_{1}, d_{1}^{\prime} f_{1}^{\prime}, d_{2 C_{3}-3} e_{1}, \\
& \left.d_{2 C_{3}-3}^{\prime} e_{2 C_{1}-3}, e_{2 C_{1}-3}^{\prime} f_{2 C_{2}-3}^{\prime}, e_{2 C_{1}-3}^{\prime} f_{2 C_{2}-3}^{\prime}, e_{1}^{\prime} f_{2 C_{2}-3}\right\} .
\end{aligned}
$$

To make it easier to grasp, we separated the various callings into groups of vertices. For example, the outside vertices of a hollow coronoid are denoted $a_{\epsilon}, a_{\epsilon}^{\prime}, b_{\epsilon}, b_{\epsilon}^{\prime}, c_{\epsilon}$ and $c_{\epsilon}^{\prime}$. The vertices inside the hollow coronoid, on the other hand, are $d_{\epsilon}, d_{\epsilon}^{\prime}, e_{\epsilon}, e_{\epsilon}^{\prime}, f_{\epsilon}$ and $f_{\epsilon}^{\prime}$. We can assign the same tasks to the edges as well. 


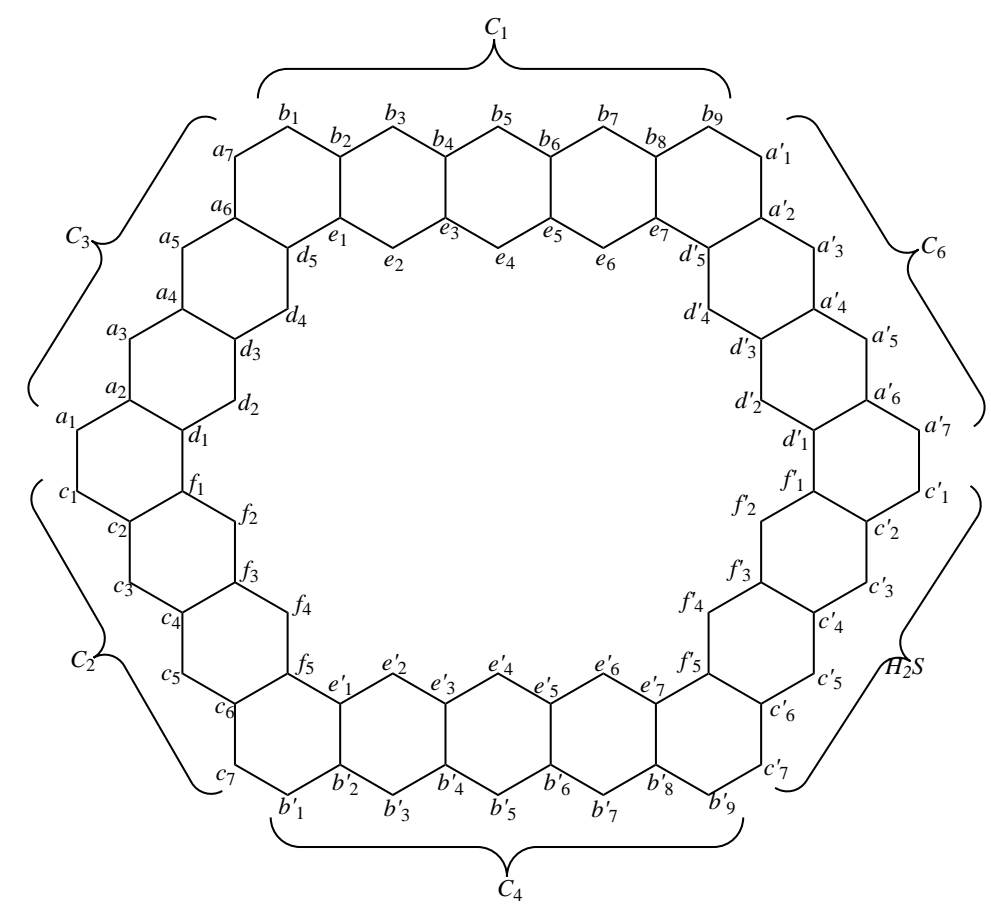

Figure 1. Hollow Coronoid with $C_{1}=5, C_{2}=C_{3}=4$.

Furthermore, by merging the vertex and edge sets of $H C\left(C_{1}, C_{2}, C_{3}\right)$, created above, the vertices marking utilized in the discoveries presented in Figure 1 , and the generalized $H C\left(C_{1}, C_{2}, C_{3}\right)$, may be constructed.

\section{The Resolvability of Hollow Coronoid Structure $\operatorname{HC}\left(C_{1}, C_{2}, C_{3}\right)$}

Given below is the main part of this study and described in Lemma 1. From $V\left(H C\left(C_{1}\right.\right.$, $\left.C_{2}, C_{3}\right)$ ), for the edge resolving set, few vertices are chosen to form a suitable subset.

Lemma 1. If $H C\left(C_{1}, C_{2}, C_{3}\right)$ is the graph of hollow coronoid setting $C_{1}, C_{2}, C_{3} \geq 2$, then the edge metric resolving set of $\mathrm{HC}\left(C_{1}, C_{2}, C_{3}\right)$ has cardinality three.

Proof. Assume $R_{e}=\left\{a_{1}, b_{1}, b_{2 C_{1}-1}\right\}$, is the edge metric resolving set with three members in it, for the hollow coronoid $\operatorname{HC}\left(C_{1}, C_{2}, C_{3}\right)$ graph. For the prove of this claim, the positions of or the identifications of edge of $H C\left(C_{1}, C_{2}, C_{3}\right)$, according to $R_{e}$, are described following. lated as;

Supposing $\epsilon=1,2, \ldots, 2 C_{3}-2$, the $I\left(a_{\epsilon} a_{\epsilon+1} \mid R_{e}\right)$ and $I\left(a_{\epsilon}^{\prime} a_{\epsilon+1}^{\prime} \mid R_{e}\right)$, are formu-

$$
\begin{aligned}
& I\left(a_{\epsilon} a_{\epsilon+1} \mid R_{e}\right)=\left(\epsilon-1,2 C_{3}-\epsilon-1,2\left(C_{3}+C_{1}\right)-\epsilon-3\right), \\
& I\left(a_{\epsilon}^{\prime} a_{\epsilon+1}^{\prime} \mid R_{e}\right)= \begin{cases}\left(2\left(2 C_{3}+C_{1}-3\right)-\epsilon, 2\left(C_{1}+C_{3}\right)-3-\epsilon, 2 C_{3}-\epsilon-1\right), & \text { if } \epsilon=1,2, \ldots, 2 C_{3}-3 ; \\
\left(2\left(C_{3}+C_{1}\right)-3,2\left(C_{1}+C_{3}\right)-3-\epsilon, 2 C_{3}-1-\epsilon\right), & \text { if } \epsilon=2 C_{3}-2 .\end{cases}
\end{aligned}
$$

Supposing $\epsilon=1,2, \ldots, 2 C_{1}-2$, the $I\left(b_{\epsilon} b_{\epsilon+1} \mid R_{e}\right)$ and $I\left(b_{\epsilon}^{\prime} b_{\epsilon+1}^{\prime} \mid R_{e}\right)$, are formulated as;

$$
\begin{aligned}
& I\left(b_{\epsilon} b_{\epsilon+1} \mid R_{e}\right)=\left(\epsilon+2\left(C_{3}-1\right), \epsilon-1,2\left(C_{1}-1\right)-\epsilon\right), \\
& I\left(b_{\epsilon}^{\prime} b_{\epsilon+1}^{\prime} \mid R_{e}\right)= \begin{cases}\left(2 C_{2}-1+\epsilon, 2\left(C_{2}+C_{3}-1\right), 2\left(C_{3}+C_{1}+C_{2}\right)-\epsilon-5\right), & \text { if } \epsilon=1 ; \\
\left(2 C_{2}-1+\epsilon, 2\left(C_{2}+C_{3}-2\right)+\epsilon, 2\left(C_{3}+C_{1}+C_{2}\right)-\epsilon-5\right), & \text { if } \epsilon=2,3, \ldots, 2 C_{1}-3 ; \\
\left(2 C_{2}-1+\epsilon, 2\left(C_{2}+C_{3}-2\right)+\epsilon, 2\left(C_{3}+C_{2}-1\right)\right), & \text { if } \epsilon=2 C_{1}-2 .\end{cases}
\end{aligned}
$$

Supposing $\epsilon=1,2, \ldots, 2 C_{2}-2$, the $I\left(c_{\epsilon} c_{\epsilon+1} \mid R_{e}\right)$ and $I\left(c_{\epsilon}^{\prime} c_{\epsilon+1}^{\prime} \mid R_{e}\right)$, are formulated as; 


$$
\begin{aligned}
& I\left(c_{\epsilon} \mathcal{c}_{\epsilon+1} \mid R_{e}\right)=\left\{\begin{array}{l}
\left(\epsilon, 2 C_{3}-1+\epsilon, 2\left(C_{3}+C_{1}\right)-3\right), \quad \text { if } \epsilon=1 ; \\
\left(\epsilon, 2 C_{3}-1+\epsilon, 2\left(C_{3}+C_{1}\right)-5+\epsilon\right), \quad \text { if } \epsilon=2,3, \ldots, 2 C_{2}-2,
\end{array}\right. \\
& I\left(c_{\epsilon}^{\prime} c_{\epsilon+1}^{\prime} \mid R_{e}\right)= \begin{cases}\left(2\left(2 C_{2}+C_{1}\right)-5-\epsilon, 2\left(C_{3}+C_{1}\right)-3,2 C_{3}-1+\epsilon\right), & \text { if } \epsilon=1 ; \\
\left(2\left(2 C_{2}+C_{1}\right)-5-\epsilon, 2\left(C_{3}+C_{1}\right)-5+\epsilon, 2 C_{3}-1+\epsilon\right), & \text { if } \epsilon=2,3, \ldots, 2 C_{2}-3 ; \\
\left(2\left(C_{2}+C_{1}-1\right), 2\left(C_{3}+C_{1}\right)-5+\epsilon, 2 C_{3}-1+\epsilon\right), & \text { if } \epsilon=2 C_{2}-2 .\end{cases}
\end{aligned}
$$

All the outside edges of $\operatorname{HC}\left(C_{1}, C_{2}, C_{3}\right)$ having unique positions or identifications with respect to $R_{e}$. The outside edges of graph $H C\left(C_{1}, C_{2}, C_{3}\right)$, given below are positions for the inside edges of same structure. lated as;

Supposing $\epsilon=1,2, \ldots, 2 C_{3}-4$, the $I\left(d_{\epsilon} d_{\epsilon+1} \mid R_{e}\right)$ and $I\left(d_{\epsilon}^{\prime} d_{\epsilon+1}^{\prime} \mid R_{e}\right)$, are formu-

$$
\begin{aligned}
& I\left(d_{\epsilon} d_{\epsilon+1} \mid R_{e}\right)=\left(\epsilon+1,2 C_{3}-1+\epsilon, 2\left(C_{3}+C_{1}\right)-5-\epsilon\right), \\
& I\left(d_{\epsilon}^{\prime} d_{\epsilon+1}^{\prime} \mid R_{e}\right)=\left(2\left(2 C_{3}+C_{1}-4\right)-\epsilon, 2\left(C_{3}+C_{1}\right)-5-\epsilon, 2 C_{3}-1-\epsilon\right) .
\end{aligned}
$$

Supposing $\epsilon=1,2, \ldots, 2 C_{1}-4$, the $I\left(e_{\epsilon} e_{\epsilon+1} \mid R_{e}\right)$ and $I\left(e_{\epsilon}^{\prime} e_{\epsilon+1}^{\prime} \mid R_{e}\right)$, are formulated as;

$$
\begin{aligned}
& I\left(e_{\epsilon} e_{\epsilon+1} \mid R_{e}\right)=\left(\epsilon+2\left(C_{3}-1\right), 1+\epsilon, 2\left(C_{1}-1\right)-\epsilon\right), \\
& I\left(e_{\epsilon}^{\prime} e_{\epsilon+1}^{\prime} \mid R_{e}\right)=\left(2 C_{2}-1+\epsilon, 2\left(C_{3}+C_{2}-2\right)+\epsilon, 2\left(C_{3}+C_{1}+C_{2}\right)-7-\epsilon\right) .
\end{aligned}
$$
lated as;

Supposing $\epsilon=1,2, \ldots, 2 C_{2}-4$, the $I\left(f_{\epsilon} f_{\epsilon+1} \mid R_{e}\right)$ and $I\left(f_{\epsilon}^{\prime} f_{\epsilon+1}^{\prime} \mid R_{e}\right)$, are formu-

$$
\begin{aligned}
& I\left(f_{\epsilon} f_{\epsilon+1} \mid R_{e}\right)=\left(\epsilon+2,2 C_{3}-1+\epsilon, 2\left(C_{1}+C_{3}\right)-5+\epsilon\right), \\
& I\left(f_{\epsilon}^{\prime} f_{\epsilon+1}^{\prime} \mid R_{e}\right)=\left(2\left(2 C_{2}+C_{1}\right)-7-\epsilon, 2\left(C_{3}+C_{1}\right)-5+\epsilon, 2 C_{3}-1+\epsilon\right) .
\end{aligned}
$$

Similar to the outside edges of $H C\left(C_{1}, C_{2}, C_{3}\right)$, we are resulted in unique positions for the inside edges as well. Proceedings are the positions of those edges which are joining the inside and outside nodes of $H C\left(C_{1}, C_{2}, C_{3}\right)$. lated as;

Supposing $\epsilon=1,3,5, \ldots, 2 C_{3}-3$, the $I\left(a_{\epsilon+1} d_{\epsilon} \mid R_{e}\right)$ and $I\left(a_{\epsilon+1}^{\prime} d_{\epsilon}^{\prime} \mid R_{e}\right)$, are formu-

$$
\begin{aligned}
& I\left(a_{\epsilon+1} d_{\epsilon} \mid R_{e}\right)=\left(\epsilon, 2 C_{3}-1-\epsilon, 2\left(C_{3}+C_{1}-2\right)-\epsilon\right), \\
& I\left(a_{\epsilon+1}^{\prime} d_{\epsilon}^{\prime} \mid R_{e}\right)=\left(2\left(2 C_{3}+C_{1}\right)-7-\epsilon, 2\left(C_{3}+C_{1}-2\right)-\epsilon, 2 C_{3}-1-\epsilon\right) .
\end{aligned}
$$

Supposing $\epsilon=1,3,5, \ldots, 2 C_{1}-3$, the $I\left(b_{\epsilon+1} e_{\epsilon} \mid R_{e}\right)$ and $I\left(b_{\epsilon+1}^{\prime} e_{\epsilon}^{\prime} \mid R_{e}\right)$, are formulated as;

$$
\begin{aligned}
& I\left(b_{\epsilon+1} e_{\epsilon} \mid R_{e}\right)=\left(\epsilon+2\left(C_{3}-1\right), \epsilon, 2\left(C_{1}-1\right)-\epsilon\right), \\
& I\left(b_{\epsilon+1}^{\prime} e_{\epsilon}^{\prime} \mid R_{e}\right)=\left(2 C_{3}-1+\epsilon, 2\left(C_{3}+C_{2}-2\right)+\epsilon, 2\left(C_{3}+C_{1}+C_{2}-3\right)-\epsilon\right) .
\end{aligned}
$$
lated as;

Supposing $\epsilon=1,3,5, \ldots, 2 C_{2}-3$, the $I\left(c_{\epsilon+1} f_{\epsilon} \mid R_{e}\right)$ and $I\left(c_{\epsilon+1}^{\prime} f_{\epsilon}^{\prime} \mid R_{e}\right)$, are formu-

$$
\begin{aligned}
& I\left(c_{\epsilon+1} f_{\epsilon} \mid R_{e}\right)=\left(\epsilon+2,2 C_{3}-1+\epsilon, 2\left(C_{1}+C_{3}\right)-5+\epsilon\right), \\
& I\left(c_{\epsilon+1}^{\prime} f_{\epsilon}^{\prime} \mid R_{e}\right)=\left(2\left(2 C_{2}+C_{1}-3\right)-\epsilon, 2\left(C_{3}+C_{1}\right)-5-\epsilon, 2 C_{3}-1+\epsilon\right) .
\end{aligned}
$$

Table 1 shows the identifications of joint edges. 
Table 1. Representation of edges with respect to resolving set $R_{e}$.

\begin{tabular}{cccc}
\hline $\boldsymbol{I}\left(. \mid \boldsymbol{R}_{\boldsymbol{e}}\right)$ & $\boldsymbol{a}_{\mathbf{1}}$ & $\boldsymbol{b}_{\mathbf{1}}$ & $\boldsymbol{b}_{2 C_{1}-\mathbf{1}}$ \\
\hline$I\left(a_{1} c_{1} \mid R_{e}\right)$ & 0 & $2 C_{3}-1$ & $2\left(C_{3}+C_{1}\right)-3$ \\
\hline$I\left(d_{1} f_{1} \mid R_{e}\right)$ & 2 & $2 C_{3}-1$ & $2\left(C_{3}+C_{1}\right)-5$ \\
\hline$I\left(a_{2 C_{3}-1} b_{1} \mid R_{e}\right)$ & $2\left(C_{3}-1\right)$ & 0 & $2\left(C_{1}-1\right)$ \\
\hline$I\left(d_{2 C_{3}-3} e_{1} \mid R_{e}\right)$ & $2\left(C_{3}-1\right)$ & 2 & $2\left(C_{1}-1\right)$ \\
\hline$I\left(b_{2 C_{1}-1} a_{2 C_{3}-1}^{\prime} \mid R_{e}\right)$ & $2\left(C_{3}+C_{1}\right)-3$ & $2\left(C_{1}-1\right)$ & 0 \\
\hline$I\left(c_{2 C_{1}-3} d_{2 C_{3}-3}^{\prime} \mid R_{e}\right)$ & $2\left(C_{3}+C_{1}\right)-5$ & $2\left(C_{1}-1\right)$ & 3 \\
\hline$I\left(d_{1}^{\prime} f_{1}^{\prime} \mid R_{e}\right)$ & $2\left(C_{3}+C_{1}-2\right)$ & $2\left(C_{1}-1\right)$ & $2 C_{3}-1$ \\
\hline$I\left(a_{1}^{\prime} c_{1}^{\prime} \mid R_{e}\right)$ & $2\left(2 C_{3}+C_{1}-3\right)$ & $2\left(C_{1}+C_{3}\right)-3$ & $2\left(C_{3}+C_{2}-2\right)$ \\
\hline$I\left(e_{2 C_{1}-3}^{\prime} f_{2 C_{2}-3}^{\prime} \mid R_{e}\right)$ & $2\left(C_{2}+C_{1}-2\right)$ & $2\left(C_{1}+C_{3}+C_{2}-3\right)$ & $2\left(C_{3}+C_{2}-1\right)$ \\
\hline$I\left(b_{2 C_{1}-1}^{\prime} c_{2 C_{2}-1}^{\prime} \mid R_{e}\right)$ & $2\left(C_{2}+C_{1}-1\right)$ & $2\left(C_{1}+C_{3}+C_{2}\right)-5$ & $2\left(C_{3}+C_{2}+C_{1}\right)-5$ \\
\hline$I\left(c_{2 C_{2}-1} b_{1}^{\prime} \mid R_{e}\right)$ & $2 C_{3}-1$ & $2\left(C_{3}+C_{2}-1\right)$ & $2\left(C_{3}+C_{2}+C_{1}\right)-7$ \\
\hline$I\left(f_{2 C_{2}-3} e_{1}^{\prime} \mid R_{e}\right)$ & $2 C_{2}-1$ & $2\left(C_{3}+C_{2}-2\right)$ &
\end{tabular}

Identifications of the entire set of line segment of graph $H C\left(C_{1}, C_{2}, C_{3}\right)$, one can examine by given above that the complete set of branches possesses the unique identifications also fulfil the concept of edge metric resolving set and finalizing that $\left|R_{e}\right|=3$.

Theorem 2. If $\mathrm{HC}\left(C_{1}, C_{2}, C_{3}\right)$ is the graph of hollow coronoid setting $C_{1}, C_{2}, C_{3} \geq 2$, then the edge metric dimension of $\mathrm{HC}\left(C_{1}, C_{2}, C_{3}\right)$ is three.

Proof. The graph $\mathrm{HC}\left(C_{1}, C_{2}, C_{3}\right)$, has edge metric dimension three; to prove this assertion, we will implement the renowned double inequality method. In the Lemma 1, we proved that $R_{e}=\left\{a_{1}, b_{1}, b_{2 C_{1}-1}\right\}$, is one of the candidate for the edge metric resolving set with three members. For the upper-bound which is resulted in $\operatorname{dim}_{e}\left(\operatorname{HC}\left(C_{1}, C_{2}, C_{3}\right)\right) \geq 3$, making its contradiction, we came to the assertion $\operatorname{dim}_{e}\left(H C\left(C_{1}, C_{2}, C_{3}\right)\right)=2$, suppose there is a volunteer of edge metric resolving set is $R_{e}^{\prime}$ with having two members. Given below are some discussion in the support of this assumption.

Let the index notations, $S_{1}=\left\{1,2, \ldots, 2 C_{3}-2\right\}, S_{2}=\left\{1,2, \ldots, 2 C_{1}-2\right\}, S_{3}=$ $\left\{1,2, \ldots, 2 C_{2}-2\right\}, S_{4}=\left\{1,2, \ldots, 2 C_{3}-4\right\}, S_{5}=\left\{1,2, \ldots, 2 C_{1}-4\right\}, S_{6}=$ $\left\{1,2, \ldots, 2 C_{2}-4\right\}, S_{7}=\left\{1,3,5, \ldots, 2 C_{3}-3\right\}, S_{8}=\left\{1,3,5, \ldots, 2 C_{1}-3\right\}$ and $S_{9}=\left\{1,3,5, \ldots, 2 C_{2}-3\right\}$.

$\star_{1}$ : Supposing $\left|R_{e}^{\prime}\right|=2$, and $R_{e}^{\prime} \subset\left\{a_{\epsilon}: 1 \leq \epsilon \leq 2 C_{3}-1\right\} \subset V\left(H C\left(C_{1}, C_{2}, C_{3}\right)\right)$. This example indicated that $\left|R_{e}^{\prime}\right| \neq 2$, with reasoning of $I\left(a_{\delta} a_{\delta+1} \mid R_{e}^{\prime}\right)=I\left(d_{m} d_{m+1} \mid R_{e}^{\prime}\right)$, where $\delta \in S_{1}$ and $m \in S_{4}$.

$\star_{2}$ : Supposing $\left|R_{e}^{\prime}\right|=2$, and $R_{e}^{\prime} \subset\left\{b_{\epsilon}: 1 \leq \epsilon \leq 2 C_{1}-1\right\} \subset V\left(H C\left(C_{1}, C_{2}, C_{3}\right)\right)$. This example indicated that $\left|R_{e}^{\prime}\right| \neq 2$, with reasoning of $I\left(a_{\delta} a_{\delta+1} \mid R_{e}^{\prime}\right)=I\left(a_{m+1} d_{m} \mid R_{e}^{\prime}\right)$, where $\delta \in S_{1}$ and $m \in S_{7}$.

$\star_{3}$ : Supposing $\left|R_{e}^{\prime}\right|=2$, and $R_{e}^{\prime} \subset\left\{c_{\epsilon}: 1 \leq \epsilon \leq 2 C_{2}-1\right\} \subset V\left(H C\left(C_{1}, C_{2}, C_{3}\right)\right)$. This example indicated that $\left|R_{e}^{\prime}\right| \neq 2$, with reasoning of $I\left(b_{\delta} b_{\delta+1} \mid R_{e}^{\prime}\right)=I\left(e_{m} e_{m+1} \mid R_{e}^{\prime}\right)$, where $\delta \in S_{2}$ and $m \in S_{5}$.

$\star_{4}$ : Supposing $\left|R_{e}^{\prime}\right|=2$, and $R_{e}^{\prime} \subset\left\{a_{\epsilon}^{\prime}: 1 \leq \epsilon \leq 2 C_{3}-1\right\} \subset V\left(H C\left(C_{1}, C_{2}, C_{3}\right)\right)$. This example indicated that $\left|R_{e}^{\prime}\right| \neq 2$, with reasoning of $I\left(b_{\delta} b_{\delta+1} \mid R_{e}^{\prime}\right)=I\left(e_{m} e_{m+1} \mid R_{e}^{\prime}\right)$, where $\delta \in S_{2}$ and $m \in S_{5}$.

$\star_{5}$ : Supposing $\left|R_{e}^{\prime}\right|=2$, and $R_{e}^{\prime} \subset\left\{b_{\epsilon}^{\prime}: 1 \leq \epsilon \leq 2 C_{1}-1\right\} \subset V\left(H C\left(C_{1}, C_{2}, C_{3}\right)\right)$. This example indicated that $\left|R_{e}^{\prime}\right| \neq 2$, with reasoning of $I\left(b_{\delta} b_{\delta+1} \mid R_{e}^{\prime}\right)=I\left(a_{m}^{\prime} a_{m+1}^{\prime} \mid R_{e}^{\prime}\right)$, where $\delta \in S_{2}$ and $m \in S_{1}$. 
$\star_{6}$ : Supposing $\left|R_{e}^{\prime}\right|=2$, and $R_{e}^{\prime} \subset\left\{c_{\epsilon}^{\prime}: 1 \leq \epsilon \leq 2 C_{2}-1\right\} \subset V\left(H C\left(C_{1}, C_{2}, C_{3}\right)\right)$. This example indicated that $\left|R_{e}^{\prime}\right| \neq 2$, with reasoning of $I\left(c_{\delta}^{\prime} c_{\delta+1}^{\prime} \mid R_{e}^{\prime}\right)=I\left(c_{m+1}^{\prime} f_{m}^{\prime} \mid R_{e}^{\prime}\right)$, where $\delta \in S_{3}$ and $m \in S_{9}$.

$\star_{7}$ : Supposing $\left|R_{e}^{\prime}\right|=2$, and $R_{e}^{\prime} \subset\left\{d_{\epsilon}: 1 \leq \epsilon \leq 2 C_{3}-3\right\} \subset V\left(H C\left(C_{1}, C_{2}, C_{3}\right)\right)$. This example indicated that $\left|R_{e}^{\prime}\right| \neq 2$, with reasoning of $I\left(b_{\delta}^{\prime} b_{\delta+1}^{\prime} \mid R_{e}^{\prime}\right)=I\left(e_{m}^{\prime} e_{m+1}^{\prime} \mid R_{e}^{\prime}\right)$, where $\delta \in S_{2}$ and $m \in S_{5}$.

$\star_{8}$ : Supposing $\left|R_{e}^{\prime}\right|=2$, and $R_{e}^{\prime} \subset\left\{e_{\epsilon}: 1 \leq \epsilon \leq 2 C_{1}-3\right\} \subset V\left(H C\left(C_{1}, C_{2}, C_{3}\right)\right)$. This example indicated that $\left|R_{e}^{\prime}\right| \neq 2$, with reasoning of $I\left(a_{\delta} a_{\delta+1} \mid R_{e}^{\prime}\right)=I\left(c_{m+1} f_{m} \mid R_{e}^{\prime}\right)$, where $\delta \in S_{1}$ and $m \in S_{9}$.

$\star_{9}$ : Supposing $\left|R_{e}^{\prime}\right|=2$, and $R_{e}^{\prime} \subset\left\{f_{\epsilon}: 1 \leq \epsilon \leq 2 C_{2}-3\right\} \subset V\left(H C\left(C_{1}, C_{2}, C_{3}\right)\right)$. This example indicated that $\left|R_{e}^{\prime}\right| \neq 2$, with reasoning of $I\left(a_{\delta} a_{\delta+1} \mid R_{e}^{\prime}\right)=I\left(a_{m+1} d_{m} \mid R_{e}^{\prime}\right)$, where $\delta \in S_{1}$ and $m \in S_{9}$.

$\star_{10}$ : Supposing $\left|R_{e}^{\prime}\right|=2$, and $R_{e}^{\prime} \subset\left\{d_{\epsilon}^{\prime}: 1 \leq \epsilon \leq 2 C_{3}-3\right\} \subset V\left(H C\left(C_{1}, C_{2}, C_{3}\right)\right)$. This example indicated that $\left|R_{e}^{\prime}\right| \neq 2$, with reasoning of $I\left(a_{\delta}^{\prime} a_{\delta+1}^{\prime} \mid R_{e}^{\prime}\right)=I\left(d_{m}^{\prime} d_{m+1}^{\prime} \mid R_{e}^{\prime}\right)$, where $\delta \in S_{1}$ and $m \in S_{4}$.

$\star_{11}$ : Supposing $\left|R_{e}^{\prime}\right|=2$, and $R_{e}^{\prime} \subset\left\{e_{\epsilon}^{\prime}: 1 \leq \epsilon \leq 2 C_{1}-3\right\} \subset V\left(H C\left(C_{1}, C_{2}, C_{3}\right)\right)$. This example indicated that $\left|R_{e}^{\prime}\right| \neq 2$, with reasoning of $I\left(b_{\delta}^{\prime} b_{\delta+1}^{\prime} \mid R_{e}^{\prime}\right)=I\left(c_{m} c_{m+1} \mid R_{e}^{\prime}\right)$, where $\delta \in S_{2}$ and $m \in S_{3}$.

$\star_{12}$ : Supposing $\left|R_{e}^{\prime}\right|=2$, and $R_{e}^{\prime} \subset\left\{f_{\epsilon}^{\prime}: 1 \leq \epsilon \leq 2 C_{2}-3\right\} \subset V\left(H C\left(C_{1}, C_{2}, C_{3}\right)\right)$. This example indicated that $\left|R_{e}^{\prime}\right| \neq 2$, with reasoning of $I\left(a_{\delta+1} d_{\delta} \mid R_{e}^{\prime}\right)=I\left(c_{m} c_{m+1} \mid R_{e}^{\prime}\right)$, where $\delta \in S_{7}$ and $m \in S_{3}$.

$\star_{13}$ : Supposing $\left|R_{e}^{\prime}\right|=2$, and $R_{e}^{\prime} \subset\left\{a_{\epsilon}, b_{j}: 1 \leq \epsilon \leq 2 C_{3}-1,1 \leq \epsilon \leq 2 C_{1}-1\right\} \subset$ $V\left(H C\left(C_{1}, C_{2}, C_{3}\right)\right)$. This example indicated that $\left|R_{e}^{\prime}\right| \neq 2$, with reasoning of $I\left(b_{\delta} b_{\delta+1} \mid R_{e}^{\prime}\right)=$ $I\left(b_{m+1} e_{m} \mid R_{e}^{\prime}\right)$, where $\delta \in S_{2}$ and $m \in S_{8}$.

$\star_{14}$ : Supposing $\left|R_{e}^{\prime}\right|=2$, and $R_{e}^{\prime} \subset\left\{a_{\epsilon}, c_{j}: 1 \leq \epsilon \leq 2 C_{3}-1,1 \leq \epsilon \leq 2 C_{2}-1\right\} \subset$ $V\left(H C\left(C_{1}, C_{2}, C_{3}\right)\right)$. This example indicated that $\left|R_{e}^{\prime}\right| \neq 2$, with reasoning of $I\left(a_{\delta}^{\prime} a_{\delta+1}^{\prime} \mid R_{e}^{\prime}\right)=$ $I\left(a_{m}^{\prime} a_{m+1}^{\prime}\right)$, where $\delta, m \in S_{1}$.

$\star_{15}$ : Supposing $\left|R_{e}^{\prime}\right|=2$, and $R_{e}^{\prime} \subset\left\{a_{\epsilon}, a_{j}^{\prime}: 1 \leq \epsilon, j \leq 2 C_{3}-1\right\} \subset V\left(H C\left(C_{1}, C_{2}, C_{3}\right)\right)$.

This example indicated that $\left|R_{e}^{\prime}\right| \neq 2$, with reasoning of $I\left(a_{\delta} a_{\delta+1} \mid R_{e}^{\prime}\right)=I\left(a_{m+1} d_{m} \mid R_{e}^{\prime}\right)$, where $\delta \in S_{1}$ and $m \in S_{7}$.

$\star_{16}$ : Supposing $\left|R_{e}^{\prime}\right|=2$, and $R_{e}^{\prime} \subset\left\{a_{\epsilon}, b_{j}^{\prime}: 1 \leq \epsilon \leq 2 C_{3}-1,1 \leq \epsilon \leq 2 C_{1}-1\right\} \subset$ $V\left(H C\left(C_{1}, C_{2}, C_{3}\right)\right)$. This example indicated that $\left|R_{e}^{\prime}\right| \neq 2$, with reasoning of $I\left(b_{\delta+1} e_{\delta} \mid R_{e}^{\prime}\right)=$ $I\left(b_{m} b_{m+1} \mid R_{e}^{\prime}\right)$, where $\delta \in S_{8}$ and $m \in S_{2}$.

$\star_{17}$ : Supposing $\left|R_{e}^{\prime}\right|=2$, and $R_{e}^{\prime} \subset\left\{a_{\epsilon}, c_{j}^{\prime}: 1 \leq \epsilon \leq 2 C_{3}-1,1 \leq \epsilon \leq 2 C_{2}-1\right\} \subset$ $V\left(H C\left(C_{1}, C_{2}, C_{3}\right)\right)$. This example indicated that $\left|R_{e}^{\prime}\right| \neq 2$, with reasoning of $I\left(c_{\delta+1} f_{\delta} \mid R_{e}^{\prime}\right)=$ $I\left(c_{m} c_{m+1} \mid R_{e}^{\prime}\right)$, where $\delta \in S_{9}$ and $m \in S_{3}$.

$\star_{18}$ : Supposing $\left|R_{e}^{\prime}\right|=2$, and $R_{e}^{\prime} \subset\left\{a_{\epsilon}, d_{j}: 1 \leq \epsilon \leq 2 C_{3}-1,1 \leq \epsilon \leq 2 C_{3}-3\right\} \subset$ $V\left(H C\left(C_{1}, C_{2}, C_{3}\right)\right)$. This example indicated that $\left|R_{e}^{\prime}\right| \neq 2$, with reasoning of $I\left(b_{\delta+1}^{\prime} e_{\delta}^{\prime} \mid R_{e}^{\prime}\right)=$ $I\left(e_{m}^{\prime} e_{m+1}^{\prime} \mid R_{e}^{\prime}\right)$, where $\delta \in S_{8}$ and $m \in S_{5}$.

$\star_{19}$ : Supposing $\left|R_{e}^{\prime}\right|=2$, and $R_{e}^{\prime} \subset\left\{a_{\epsilon}, e_{j}: 1 \leq \epsilon \leq 2 C_{3}-1,1 \leq \epsilon \leq 2 C_{1}-3\right\} \subset$ $V\left(H C\left(C_{1}, C_{2}, C_{3}\right)\right)$. This example indicated that $\left|R_{e}^{\prime}\right| \neq 2$, with reasoning of $I\left(a_{\delta} a_{\delta+1} \mid R_{e}^{\prime}\right)=$ $I\left(d_{m} d_{m+1} \mid R_{e}^{\prime}\right)$, where $\delta \in S_{1}$ and $m \in S_{4}$.

$\star_{20}$ : Supposing $\left|R_{e}^{\prime}\right|=2$, and $R_{e}^{\prime} \subset\left\{a_{\epsilon}, f_{j}: 1 \leq \epsilon \leq 2 C_{3}-1,1 \leq \epsilon \leq 2 C_{2}-3\right\} \subset$ $V\left(H C\left(C_{1}, C_{2}, C_{3}\right)\right)$. This example indicated that $\left|R_{e}^{\prime}\right| \neq 2$, with reasoning of $I\left(b_{\delta}^{\prime} b_{\delta+1}^{\prime} \mid R_{e}^{\prime}\right)=$ $I\left(e_{m}^{\prime} e_{m+1}^{\prime} \mid R_{e}^{\prime}\right)$, where $\delta \in S_{2}$ and $m \in S_{5}$.

$\star_{21}$ : Supposing $\left|R_{e}^{\prime}\right|=2$, and $R_{e}^{\prime} \subset\left\{a_{\epsilon}, d_{j}^{\prime}: 1 \leq \epsilon \leq 2 C_{3}-1,1 \leq \epsilon \leq 2 C_{3}-3\right\} \subset$ $V\left(H C\left(C_{1}, C_{2}, C_{3}\right)\right)$. This example indicated that $\left|R_{e}^{\prime}\right| \neq 2$, with reasoning of $I\left(a_{\delta}^{\prime} a_{\delta+1}^{\prime} \mid R_{e}^{\prime}\right)=$ $I\left(d_{m}^{\prime} d_{m+1}^{\prime} \mid R_{e}^{\prime}\right)$, where $\delta \in S_{1}$ and $m \in S_{4}$.

$\star_{22}$ : Supposing $\left|R_{e}^{\prime}\right|=2$, and $R_{e}^{\prime} \subset\left\{a_{\epsilon}, e_{j}^{\prime}: 1 \leq \epsilon \leq 2 C_{3}-1,1 \leq \epsilon \leq 2 C_{1}-3\right\} \subset$ $V\left(H C\left(C_{1}, C_{2}, C_{3}\right)\right)$. This example indicated that $\left|R_{e}^{\prime}\right| \neq 2$, with reasoning of $I\left(c_{\delta+1} f_{\delta} \mid R_{e}^{\prime}\right)=$ $I\left(c_{m} c_{m+1} \mid R_{e}^{\prime}\right)$, where $\delta \in S_{9}$ and $m \in S_{3}$. 
$\star_{23}$ : Supposing $\left|R_{e}^{\prime}\right|=2$, and $R_{e}^{\prime} \subset\left\{a_{\epsilon}, f_{j}^{\prime}: 1 \leq \epsilon \leq 2 C_{3}-1,1 \leq \epsilon \leq 2 C_{2}-3\right\} \subset$ $V\left(H C\left(C_{1}, C_{2}, C_{3}\right)\right)$. This example indicated that $\left|R_{e}^{\prime}\right| \neq 2$, with reasoning of $I\left(c_{\delta+1} f_{\delta} \mid R_{e}^{\prime}\right)=$ $I\left(c_{m} c_{m+1} \mid R_{e}^{\prime}\right)$, where $\delta \in S_{9}$ and $m \in S_{3}$.

Analogously, from the above discussion we can observe that we are unable to get a single candidate from the possible combinations which are $\left|V\left(H C\left(C_{1}, C_{2}, C_{3}\right)\right)\right| C_{2}=\frac{\left|V\left(H C\left(C_{1}, C_{2}, C_{3}\right)\right)\right| !}{2 !\left(\left|V\left(H C\left(C_{1}, C_{2}, C_{3}\right)\right)\right|-2\right) !}$ $=\frac{\left(8\left(C_{1}+C_{2}+C_{3}-3\right)\right) !}{2 \times\left(8\left(C_{1}+C_{2}+C_{3}-3\right)\right) !}$ of the set of all principle nodes of hollow coronoid graph $H C\left(C_{1}, C_{2}, C_{3}\right)$. This indicated that the edge metric dimension of $\operatorname{HC}\left(C_{1}, C_{2}, C_{3}\right), 2$ is does not exist. Hence; $\operatorname{dim}_{e}\left(H C\left(C_{1}, C_{2}, C_{3}\right)\right) \geq 3$.

By summing up both acquired inequalities, we examine the fact that

$$
\operatorname{dim}_{e}\left(H C\left(C_{1}, C_{2}, C_{3}\right)\right)=3 .
$$

Lemma 2. If $H C\left(C_{1}, C_{2}, C_{3}\right)$ is the graph of hollow coronoid setting $C_{1}, C_{2}, C_{3} \geq 2$, then the fault-tolerant edge metric resolving set of $H C\left(C_{1}, C_{2}, C_{3}\right)$ has cardinality four.

Proof. Assume $R_{e, f}=\left\{a_{1}, b_{1}, b_{2 C_{1}-1}, e_{2 C_{1}-3}^{\prime}\right\}$, is the fault-tolerant edge metric resolving set with four members in it, for the hollow coronoid $H C\left(C_{1}, C_{2}, C_{3}\right)$ graph. For the prove of this claim, the positions of or the identifications of edge of $H C\left(C_{1}, C_{2}, C_{3}\right)$, according to $R_{e, f}$, are described following.

We divide the proof into two following cases on the values of $C_{1}, C_{2}$ and $C_{3}$.

$\star_{1}$ : When $C_{1}=2,3$ and $C_{2}=C_{3}=2$. lated as;

Supposing $\epsilon=1,2, \ldots, 2 C_{3}-2$, the $I\left(a_{\epsilon} a_{\epsilon+1} \mid R_{e, f}\right)$ and $I\left(a_{\epsilon}^{\prime} a_{\epsilon+1}^{\prime} \mid R_{e, f}\right)$, are formu-

$$
\begin{aligned}
& I\left(a_{\epsilon} a_{\epsilon+1} \mid R_{e, f}\right)=\left\{\begin{array}{l}
\left(\epsilon-1,2 C_{3}-\epsilon-1,2\left(C_{3}+C_{1}\right)-\epsilon-3,2 C_{1}+1\right), \quad \text { if } \epsilon=1 ; \\
\left(\epsilon-1,2 C_{3}-\epsilon-1,2\left(C_{3}+C_{1}\right)-\epsilon-3,2 C_{1}+1\right), \quad \text { if } \epsilon=2,3, \ldots, 2 C_{3}-2 .
\end{array}\right. \\
& I\left(a_{\epsilon}^{\prime} a_{\epsilon+1}^{\prime} \mid R_{e, f}\right)=\left\{\begin{array}{l}
\left(2\left(2 C_{3}+C_{1}-3\right)-\epsilon, 2\left(C_{1}+C_{3}\right)-3-\epsilon, 2 C_{3}-\epsilon-1, \epsilon-1\right), \\
\left(2\left(2 C_{3}+C_{1}-3\right)-\epsilon, 2\left(C_{1}+C_{3}\right)-3-\epsilon, 2 C_{3}-\epsilon-1,2 C_{2}, \epsilon-1\right), \\
\text { if } \epsilon=2,3, \ldots, 2 C_{3}-3 \\
\left(2\left(C_{3}+C_{1}\right)-3,2\left(C_{1}+C_{3}\right)-3-\epsilon, 2 C_{3}-1-\epsilon, \epsilon-1\right),
\end{array}\right.
\end{aligned}
$$
lated as;

Supposing $\epsilon=1,2, \ldots, 2 C_{1}-2$, the $I\left(b_{\epsilon} b_{\epsilon+1} \mid R_{e, f}\right)$ and $I\left(b_{\epsilon}^{\prime} b_{\epsilon+1}^{\prime} \mid R_{e, f}\right)$, are formu-

$$
\begin{aligned}
I\left(b_{\epsilon} b_{\epsilon+1} \mid R_{e, f}\right)= & \left(\epsilon+2\left(C_{3}-1\right), \epsilon-1,2\left(C_{1}-1\right)-\epsilon, 2 C_{1}+1-\epsilon\right), \\
I\left(b_{\epsilon}^{\prime} b_{\epsilon+1}^{\prime} \mid R_{e, f}\right)= & \left\{\begin{array}{l}
\left(2 C_{2}-1+\epsilon, 2\left(C_{2}+C_{3}-1\right), 2\left(C_{3}+C_{1}+C_{2}\right)-\epsilon-5,2\left(C_{1}+1\right)-\epsilon\right), \\
\text { if } \epsilon=1 ; \\
\left(2 C_{2}-1+\epsilon, 2\left(C_{2}+C_{3}-2\right)+\epsilon, 2\left(C_{3}+C_{1}+C_{2}\right)-\epsilon-5,2\left(C_{1}+1\right)-\epsilon\right), \\
\text { if } \epsilon=2,3, \ldots, 2 C_{1}-3 ; \\
\left(2 C_{2}-1+\epsilon, 2\left(C_{2}+C_{3}-2\right)+\epsilon, 2\left(C_{3}+C_{2}-1\right), 2\left(C_{1}+1\right)-\epsilon\right), \\
\text { if } \epsilon=2 C_{1}-2 .
\end{array}\right.
\end{aligned}
$$
lated as;

Supposing $\epsilon=1,2, \ldots, 2 C_{2}-2$, the $I\left(c_{\epsilon} c_{\epsilon+1} \mid R_{e, f}\right)$ and $I\left(c_{\epsilon}^{\prime} c_{\epsilon+1}^{\prime} \mid R_{e, f}\right)$, are formu- 


$$
\begin{aligned}
& I\left(c_{\epsilon} \mathcal{c}_{\epsilon+1} \mid R_{e, f}\right)= \begin{cases}\left(\epsilon, 2 C_{3}-1+\epsilon, 2\left(C_{3}+C_{1}\right)-3,2 C_{1}+2\right), & \text { if } \epsilon=1 ; \\
\left(\epsilon, 2 C_{3}-1+\epsilon, 2\left(C_{3}+C_{1}\right)-5+\epsilon, 2 C_{1}+2\right), & \text { if } \epsilon=2,3, \ldots, 2 C_{2}-2,\end{cases} \\
& I\left(c_{\epsilon}^{\prime} c_{\epsilon+1}^{\prime} \mid R_{e, f}\right)= \begin{cases}\left(2\left(2 C_{2}+C_{1}\right)-5-\epsilon, 2\left(C_{3}+C_{1}\right)-3,2 C_{3}-1+\epsilon, 1\right), & \text { if } \epsilon=1 ; \\
\left(2\left(2 C_{2}+C_{1}\right)-5-\epsilon, 2\left(C_{3}+C_{1}\right)-5+\epsilon, 2 C_{3}-1+\epsilon, 1\right), & \text { if } \epsilon=2,3, \ldots, 2 C_{2}-3 ; \\
\left(2\left(C_{2}+C_{1}-1\right), 2\left(C_{3}+C_{1}\right)-5+\epsilon, 2 C_{3}-1+\epsilon, 1\right), & \text { if } \epsilon=2 C_{2}-2 .\end{cases}
\end{aligned}
$$

All the outside edges of $\mathrm{HC}\left(C_{1}, C_{2}, C_{3}\right)$ having unique positions or identifications with respect to $R_{e, f}$. The outside edges of graph $H C\left(C_{1}, C_{2}, C_{3}\right)$, given below are positions for the inside edges of same structure.

Supposing $\epsilon=1,2, \ldots, 2 C_{1}-4$, the $I\left(e_{\epsilon} e_{\epsilon+1} \mid R_{e, f}\right)$ and $I\left(e_{\epsilon}^{\prime} e_{\epsilon+1}^{\prime} \mid R_{e, f}\right)$, are formulated as;

$$
\begin{aligned}
& I\left(e_{\epsilon} e_{\epsilon+1} \mid R_{e, f}\right)=\left(\epsilon+2\left(C_{3}-1\right), 1+\epsilon, 2\left(C_{1}-1\right)-\epsilon, 5-\epsilon\right), \\
& I\left(e_{\epsilon}^{\prime} e_{\epsilon+1}^{\prime} \mid R_{e, f}\right)=\left(2 C_{2}-1+\epsilon, 2\left(C_{3}+C_{2}-2\right)+\epsilon, 2\left(C_{3}+C_{1}+C_{2}\right)-7-\epsilon, 5-\epsilon\right) .
\end{aligned}
$$

Similar to the outside edges of $H C\left(C_{1}, C_{2}, C_{3}\right)$, we are resulted in unique positions for the inside edges as well. Proceedings are the positions of those edges which are joining the inside and outside nodes of $H C\left(C_{1}, C_{2}, C_{3}\right)$.

Supposing $\epsilon=1,3,5, \ldots, 2 C_{3}-3$, the $I\left(a_{\epsilon+1} d_{\epsilon} \mid R_{e, f}\right)$ and $I\left(a_{\epsilon+1}^{\prime} d_{\epsilon}^{\prime} \mid R_{e, f}\right)$, are formulated as;

$$
\begin{aligned}
& I\left(a_{\epsilon+1} d_{\epsilon} \mid R_{e, f}\right)=\left(\epsilon, 2 C_{3}-1-\epsilon, 2\left(C_{3}+C_{1}-2\right)-\epsilon, 2 C_{1}\right), \\
& I\left(a_{\epsilon+1}^{\prime} d_{\epsilon}^{\prime} \mid R_{e, f}\right)=\left(2\left(2 C_{3}+C_{1}\right)-7-\epsilon, 2\left(C_{3}+C_{1}-2\right)-\epsilon, 2 C_{3}-1-\epsilon, 1\right) .
\end{aligned}
$$

Supposing $\epsilon=1,3,5, \ldots, 2 C_{1}-3$, the $I\left(b_{\epsilon+1} e_{\epsilon} \mid R_{e, f}\right)$ and $I\left(b_{\epsilon+1}^{\prime} e_{\epsilon}^{\prime} \mid R_{e, f}\right)$, are formulated as;

$$
\begin{aligned}
& I\left(b_{\epsilon+1} e_{\epsilon} \mid R_{e, f}\right)=\left(\epsilon+2\left(C_{3}-1\right), \epsilon, 2\left(C_{1}-1\right)-\epsilon, 2 C_{1}-\epsilon\right), \\
& I\left(b_{\epsilon+1}^{\prime} e_{\epsilon}^{\prime} \mid R_{e, f}\right)=\left(2 C_{3}-1+\epsilon, 2\left(C_{3}+C_{2}-2\right)+\epsilon, 2\left(C_{3}+C_{1}+C_{2}-3\right)-\epsilon, 2 C_{1}+1-\epsilon\right) .
\end{aligned}
$$

Supposing $\epsilon=1,3,5, \ldots, 2 C_{2}-3$, the $I\left(c_{\epsilon+1} f_{\epsilon} \mid R_{e, f}\right)$ and $I\left(c_{\epsilon+1}^{\prime} f_{\epsilon}^{\prime} \mid R_{e, f}\right)$, are formulated as;

$$
\begin{aligned}
& I\left(c_{\epsilon+1} f_{\epsilon} \mid R_{e, f}\right)=\left(\epsilon+2,2 C_{3}-1+\epsilon, 2\left(C_{1}+C_{3}\right)-5+\epsilon, 2 C_{1}+1\right), \\
& I\left(c_{\epsilon+1}^{\prime} f_{\epsilon}^{\prime} \mid R_{e, f}\right)=\left(2\left(2 C_{2}+C_{1}-3\right)-\epsilon, 2\left(C_{3}+C_{1}\right)-5-\epsilon, 2 C_{3}-1+\epsilon, 2\right) .
\end{aligned}
$$

Table 2 shows the identifications of joint edges.

$\star_{2}$ : When $C_{1}, C_{2}, C_{3} \geq 3$. lated as;

Supposing $\epsilon=1,2, \ldots, 2 C_{3}-2$, the $I\left(a_{\epsilon} a_{\epsilon+1} \mid R_{e, f}\right)$ and $I\left(a_{\epsilon}^{\prime} a_{\epsilon+1}^{\prime} \mid R_{e, f}\right)$, are formu- 


$$
\begin{aligned}
& I\left(a_{\epsilon} a_{\epsilon+1} \mid R_{e, f}\right)=\left\{\begin{array}{l}
\left(\epsilon-1,2 C_{3}-\epsilon-1,2\left(C_{3}+C_{1}\right)-\epsilon-3,2\left(C_{1}+C_{2}\right)-5\right), \quad \text { if } \epsilon=1 \\
\left(\epsilon-1,2 C_{3}-\epsilon-1,2\left(C_{3}+C_{1}\right)-\epsilon-3,2\left(C_{1}+C_{2}\right)-7+\epsilon\right), \\
\text { if } \epsilon=2,3, \ldots, 2 C_{3}-2 .
\end{array}\right. \\
& I\left(a_{\epsilon}^{\prime} a_{\epsilon+1}^{\prime} \mid R_{e, f}\right)=\left\{\begin{array}{l}
\left(2\left(2 C_{3}+C_{1}-3\right)-\epsilon, 2\left(C_{1}+C_{3}\right)-3-\epsilon, 2 C_{3}-\epsilon-1,2 C_{2}-1\right), \quad \text { if } \epsilon=1 ; \\
\left(2\left(2 C_{3}+C_{1}-3\right)-\epsilon, 2\left(C_{1}+C_{3}\right)-3-\epsilon, 2 C_{3}-\epsilon-1,2 C_{2}-3+\epsilon\right), \\
\text { if } \epsilon=2,3, \ldots, 2 C_{3}-3 \\
\left(2\left(C_{3}+C_{1}\right)-3,2\left(C_{1}+C_{3}\right)-3-\epsilon, 2 C_{3}-1-\epsilon, 2 C_{2}-3+\epsilon\right), \\
\text { if } \epsilon=2 C_{3}-2 .
\end{array}\right. \\
& \text { lated as; } \\
& \text { Supposing } \epsilon=1,2, \ldots, 2 C_{1}-2, \text { the } I\left(b_{\epsilon} b_{\epsilon+1} \mid R_{e, f}\right) \text { and } I\left(b_{\epsilon}^{\prime} b_{\epsilon+1}^{\prime} \mid R_{e, f}\right) \text {, are formu- } \\
& I\left(b_{\epsilon} b_{\epsilon+1} \mid R_{e, f}\right)=\left\{\begin{array}{l}
\left(\epsilon+2\left(C_{3}-1\right), \epsilon-1,2\left(C_{1}-1\right)-\epsilon, 2\left(C_{1}+C_{2}+C_{3}\right)-7-\epsilon\right), \\
\text { if } \epsilon=1,2, \ldots, 2 C_{1}-3 \\
\left(\epsilon+2\left(C_{3}-1\right), \epsilon-1,2\left(C_{1}-1\right)-\epsilon, 2\left(C_{2}+C_{3}-2\right)\right), \\
\text { if } \epsilon=2 C_{1}-2 .
\end{array}\right. \\
& I\left(b_{\epsilon}^{\prime} b_{\epsilon+1}^{\prime} \mid R_{e, f}\right)=\left\{\begin{array}{l}
\left(2 C_{2}-1+\epsilon, 2\left(C_{2}+C_{3}-1\right), 2\left(C_{3}+C_{1}+C_{2}\right)-\epsilon-5,2\left(C_{1}-1\right)-\epsilon\right) \\
\text { if } \epsilon=1 \\
\left(2 C_{2}-1+\epsilon, 2\left(C_{2}+C_{3}-2\right)+\epsilon, 2\left(C_{3}+C_{1}+C_{2}\right)-\epsilon-5,2\left(C_{1}-1\right)-\epsilon\right) \\
\text { if } \epsilon=2,3, \ldots, 2 C_{1}-3 \\
\left(2 C_{2}-1+\epsilon, 2\left(C_{2}+C_{3}-2\right)+\epsilon, 2\left(C_{3}+C_{2}-1\right), 2\right) \\
\text { if } \epsilon=2 C_{1}-2 .
\end{array}\right. \\
& I\left(c_{\epsilon} \mathcal{C}_{\epsilon+1} \mid R_{e, f}\right)= \begin{cases}\left(\epsilon, 2 C_{3}-1+\epsilon, 2\left(C_{3}+C_{1}\right)-3,2\left(C_{2}+C_{1}\right)-5-\epsilon\right), & \text { if } \epsilon=1 ; \\
\left(\epsilon, 2 C_{3}-1+\epsilon, 2\left(C_{3}+C_{1}\right)-5+\epsilon, 2\left(C_{2}+C_{1}\right)-5-\epsilon\right), & \text { if } \epsilon=2,3, \ldots, 2 C_{2}-3 ; \\
\left(\epsilon, 2 C_{3}-1+\epsilon, 2\left(C_{3}+C_{1}\right)-5+\epsilon, 2\left(C_{1}-1\right)\right), & \text { if } \epsilon=2 C_{2}-2,\end{cases} \\
& I\left(c_{\epsilon}^{\prime} c_{\epsilon+1}^{\prime} \mid R_{e, f}\right)= \begin{cases}\left(2\left(2 C_{2}+C_{1}\right)-5-\epsilon, 2\left(C_{3}+C_{1}\right)-3,2 C_{3}-1+\epsilon, 2 C_{2}-1-\epsilon\right), & \text { if } \epsilon=1 ; \\
\left(2\left(2 C_{2}+C_{1}\right)-5-\epsilon, 2\left(C_{3}+C_{1}\right)-5+\epsilon, 2 C_{3}-1+\epsilon, 2 C_{2}-1-\epsilon\right), & \\
\text { if } \epsilon=2,3, \ldots, 2 C_{2}-3 ; & \text { if } \epsilon=2 C_{2}-2 . \\
\left(2\left(C_{2}+C_{1}-1\right), 2\left(C_{3}+C_{1}\right)-5+\epsilon, 2 C_{3}-1+\epsilon, 3\right), & .\end{cases}
\end{aligned}
$$

All the outside edges of $\operatorname{HC}\left(C_{1}, C_{2}, C_{3}\right)$ having unique positions or identifications with respect to $R_{e, f}$. The outside edges of graph $H C\left(C_{1}, C_{2}, C_{3}\right)$, given below are positions for the inside edges of same structure. lated as;

Supposing $\epsilon=1,2, \ldots, 2 C_{3}-4$, the $I\left(d_{\epsilon} d_{\epsilon+1} \mid R_{e, f}\right)$ and $I\left(d_{\epsilon}^{\prime} d_{\epsilon+1}^{\prime} \mid R_{e, f}\right)$, are formu-

$$
\begin{aligned}
& I\left(d_{\epsilon} d_{\epsilon+1} \mid R_{e, f}\right)=\left(\epsilon+1,2 C_{3}-1+\epsilon, 2\left(C_{3}+C_{1}\right)-5-\epsilon, 2\left(C_{3}+C_{1}\right)-7+\epsilon\right), \\
& I\left(d_{\epsilon}^{\prime} d_{\epsilon+1}^{\prime} \mid R_{e, f}\right)=\left(2\left(2 C_{3}+C_{1}-4\right)-\epsilon, 2\left(C_{3}+C_{1}\right)-5-\epsilon, 2 C_{3}-1-\epsilon, 2 C_{2}-3+\epsilon\right) .
\end{aligned}
$$
lated as;

Supposing $\epsilon=1,2, \ldots, 2 C_{1}-4$, the $I\left(e_{\epsilon} e_{\epsilon+1} \mid R_{e, f}\right)$ and $I\left(e_{\epsilon}^{\prime} e_{\epsilon+1}^{\prime} \mid R_{e, f}\right)$, are formu- 


$$
\begin{aligned}
& I\left(e_{\epsilon} e_{\epsilon+1} \mid R_{e, f}\right)=\left(\epsilon+2\left(C_{3}-1\right), 1+\epsilon, 2\left(C_{1}-1\right)-\epsilon, 2\left(C_{3}+C_{1}+C_{2}\right)-9-\epsilon\right) \\
& I\left(e_{\epsilon}^{\prime} e_{\epsilon+1}^{\prime} \mid R_{e, f}\right)=\left(2 C_{2}-1+\epsilon, 2\left(C_{3}+C_{2}-2\right)+\epsilon, 2\left(C_{3}+C_{1}+C_{2}\right)-7-\epsilon, 2\left(C_{1}-1\right)-\epsilon\right) .
\end{aligned}
$$

Supposing $\epsilon=1,2, \ldots, 2 C_{2}-4$, the $I\left(f_{\epsilon} f_{\epsilon+1} \mid R_{e, f}\right)$ and $I\left(f_{\epsilon}^{\prime} f_{\epsilon+1}^{\prime} \mid R_{e, f}\right)$, are formulated as;

$$
\begin{aligned}
& I\left(f_{\epsilon} f_{\epsilon+1} \mid R_{e, f}\right)=\left(\epsilon+2,2 C_{3}-1+\epsilon, 2\left(C_{1}+C_{3}\right)-5+\epsilon, 2\left(C_{2}+C_{1}\right)-7-\epsilon\right), \\
& I\left(f_{\epsilon}^{\prime} f_{\epsilon+1}^{\prime} \mid R_{e, f}\right)=\left(2\left(2 C_{2}+C_{1}\right)-7-\epsilon, 2\left(C_{3}+C_{1}\right)-5+\epsilon, 2 C_{3}-1+\epsilon, 2 C_{2}-3-\epsilon\right) .
\end{aligned}
$$

Similar to the outside edges of $H C\left(C_{1}, C_{2}, C_{3}\right)$, we are resulted in unique positions for the inside edges as well. Proceedings are the positions of those edges which are joining the inside and outside nodes of $\mathrm{HC}\left(C_{1}, C_{2}, C_{3}\right)$.

Supposing $\epsilon=1,3,5, \ldots, 2 C_{3}-3$, the $I\left(a_{\epsilon+1} d_{\epsilon} \mid R_{e, f}\right)$ and $I\left(a_{\epsilon+1}^{\prime} d_{\epsilon}^{\prime} \mid R_{e, f}\right)$, are formulated as;

$$
\begin{aligned}
& I\left(a_{\epsilon+1} d_{\epsilon} \mid R_{e, f}\right)=\left(\epsilon, 2 C_{3}-1-\epsilon, 2\left(C_{3}+C_{1}-2\right)-\epsilon, 2\left(C_{1}+C_{2}\right)-7+\epsilon\right), \\
& I\left(a_{\epsilon+1}^{\prime} d_{\epsilon}^{\prime} \mid R_{e, f}\right)=\left(2\left(2 C_{3}+C_{1}\right)-7-\epsilon, 2\left(C_{3}+C_{1}-2\right)-\epsilon, 2 C_{3}-1-\epsilon, 2 C_{2}-3+\epsilon\right) .
\end{aligned}
$$

Supposing $\epsilon=1,3,5, \ldots, 2 C_{1}-3$, the $I\left(b_{\epsilon+1} e_{\epsilon} \mid R_{e, f}\right)$ and $I\left(b_{\epsilon+1}^{\prime} e_{\epsilon}^{\prime} \mid R_{e, f}\right)$, are formulated as;

$$
\begin{aligned}
& I\left(b_{\epsilon+1} e_{\epsilon} \mid R_{e, f}\right)=\left(\epsilon+2\left(C_{3}-1\right), \epsilon, 2\left(C_{1}-1\right)-\epsilon, 2\left(C_{2}+C_{3}+C_{1}-4\right)-\epsilon\right), \\
& I\left(b_{\epsilon+1}^{\prime} e_{\epsilon}^{\prime} \mid R_{e, f}\right)=\left(2 C_{3}-1+\epsilon, 2\left(C_{3}+C_{2}-2\right)+\epsilon, 2\left(C_{3}+C_{1}+C_{2}-3\right)-\epsilon, 2 C_{1}-3-\epsilon\right) .
\end{aligned}
$$

Supposing $\epsilon=1,3,5, \ldots, 2 C_{2}-3$, the $I\left(c_{\epsilon+1} f_{\epsilon} \mid R_{e, f}\right)$ and $I\left(c_{\epsilon+1}^{\prime} f_{\epsilon}^{\prime} \mid R_{e, f}\right)$, are formulated as;

$$
\begin{aligned}
& I\left(c_{\epsilon+1} f_{\epsilon} \mid R_{e, f}\right)=\left(\epsilon+2,2 C_{3}-1+\epsilon, 2\left(C_{1}+C_{3}\right)-5+\epsilon, 2\left(C_{2}+C_{1}-3\right)-\epsilon\right), \\
& I\left(c_{\epsilon+1}^{\prime} f_{\epsilon}^{\prime} \mid R_{e, f}\right)=\left(2\left(2 C_{2}+C_{1}-3\right)-\epsilon, 2\left(C_{3}+C_{1}\right)-5-\epsilon, 2 C_{3}-1+\epsilon, 2\left(C_{2}-1\right)-\epsilon\right) .
\end{aligned}
$$

Table 2 shows the identifications of joint edges.

Identifications of the entire set of line segment of graph $\mathrm{HC}\left(C_{1}, C_{2}, C_{3}\right)$, one can examine by given above that the complete set of branches possesses the unique positions also fulfil the concept of edge metric resolving set and finalizing that $\left|R_{e, f}\right|=4$.

Theorem 3. If $\mathrm{HC}\left(C_{1}, C_{2}, C_{3}\right)$ is the graph of hollow coronoid setting $C_{1}, C_{2}, C_{3} \geq 2$, then the fault-tolerant edge metric dimension of $\operatorname{HC}\left(C_{1}, C_{2}, C_{3}\right)$ is four.

Proof. The graph $\mathrm{HC}\left(C_{1}, C_{2}, C_{3}\right)$, has fault-tolerant edge metric dimension four, to prove this assertion we will implement the renowned double inequality method. In the Lemma 1 , we proved that $R_{e, f}=\left\{a_{1}, b_{1}, b_{2 C_{1}-1}, e_{2 C_{1}-3}^{\prime}\right\}$, is one of the candidate for the faulttolerant edge metric resolving set with four members. For the upper-bound which is resulted in $\operatorname{dim}_{e, f}\left(H C\left(C_{1}, C_{2}, C_{3}\right)\right) \geq 4$, making its contradiction, we came to the assertion $\operatorname{dim}_{e, f}\left(H C\left(C_{1}, C_{2}, C_{3}\right)\right)=3$, now and by referring the Theorem 1 and Theorem 2 concluded that 3 fault-tolerant edge metric dimension of $H C\left(C_{1}, C_{2}, C_{3}\right)$, is does not exist. Hence; $\operatorname{dim}_{e, f}\left(H C\left(C_{1}, C_{2}, C_{3}\right)\right) \geq 4$. 
By summing up both acquired inequalities, we examine the fact that

$$
\operatorname{dim}_{e, f}\left(H C\left(C_{1}, C_{2}, C_{3}\right)\right)=4
$$

Table 2. Representation of edges with respect to resolving set $R_{e, f}$.

\begin{tabular}{|c|c|c|c|c|}
\hline$I\left(. \mid R_{e, f}\right)$ & $a_{1}$ & $b_{1}$ & $b_{2 C_{1}-1}$ & $a_{1}^{\prime}$ \\
\hline$I\left(a_{1} c_{1} \mid R_{e, f}\right)$ & 0 & $2 C_{3}-1$ & $2\left(C_{3}+C_{1}\right)-3$ & $2\left(C_{1}+1\right)$ \\
\hline$I\left(d_{1} f_{1} \mid R_{e, f}\right)$ & 2 & $2 C_{3}-1$ & $2\left(C_{3}+C_{1}\right)-5$ & $2 C_{1}$ \\
\hline$I\left(a_{2 C_{3}-1} b_{1} \mid R_{e, f}\right)$ & $2\left(C_{3}-1\right)$ & 0 & $2\left(C_{1}-1\right)$ & $2 C_{1}+1$ \\
\hline$I\left(d_{2 C_{3}-3} e_{1} \mid R_{e, f}\right)$ & $2\left(C_{3}-1\right)$ & 2 & $2\left(C_{1}-1\right)$ & $2 C_{1}-1$ \\
\hline$I\left(b_{2 C_{1}-1} a_{2 C_{3}-1}^{\prime} \mid R_{e, f}\right)$ & $2\left(C_{3}+C_{1}\right)-3$ & $2\left(C_{1}-1\right)$ & 0 & 2 \\
\hline$I\left(c_{2 C_{1}-3} d_{2 C_{3}-3}^{\prime} \mid R_{e, f}\right)$ & $2\left(C_{3}+C_{1}\right)-5$ & $2\left(C_{1}-1\right)$ & 2 & 2 \\
\hline$I\left(d_{1}^{\prime} f_{1}^{\prime} \mid R_{e, f}\right)$ & $2\left(C_{3}+C_{1}-2\right)$ & $2\left(C_{1}-1\right)$ & 3 & 2 \\
\hline$I\left(a_{1}^{\prime} c_{1}^{\prime} \mid R_{e, f}\right)$ & $2\left(2 C_{3}+C_{1}-3\right)$ & $2\left(C_{1}+C_{3}\right)-3$ & $2 C_{3}-1$ & 0 \\
\hline$I\left(e_{2 C_{1}-3}^{\prime} f_{2 C_{2}-3}^{\prime} \mid I\right.$ & $2\left(C_{2}+C_{1}-2\right)$ & $2\left(C_{1}+C_{3}+C_{2}-3\right)$ & $2\left(C_{3}+C_{2}-2\right)$ & 3 \\
\hline$I\left(b_{2 C_{1}-1}^{\prime} c_{2 C_{2}-1}^{\prime} \mid R_{e, f}\right)$ & $2\left(C_{2}+C_{1}-1\right)$ & $2\left(C_{1}+C_{3}+C_{2}\right)-5$ & $2\left(C_{3}+C_{2}-1\right)$ & 3 \\
\hline$I\left(c_{2 C_{2}-1} b_{1}^{\prime} \mid R_{e, f}\right.$ & $2 C_{3}-1$ & $2\left(C_{3}+C_{2}-1\right)$ & $2\left(C_{3}+C_{2}+C_{1}\right)-5$ & $2\left(C_{1}+1\right)$ \\
\hline$I\left(f_{2 C_{2}-3} e_{1}^{\prime} \mid R_{e, f}\right.$ & $2 C_{2}-1$ & $2\left(C_{3}+C_{2}-2\right)$ & $2\left(C_{3}+C_{2}+C_{1}\right)-7$ & $2 C_{1}$ \\
\hline$I\left(. \mid R_{e, f}\right)$ & $a_{1}$ & $b_{1}$ & $b_{2 C_{1}-1}$ & $e_{2 C_{1}-3}^{\prime}$ \\
\hline$I\left(a_{1} c_{1} \mid R_{e, f}\right)$ & 0 & $2 C_{3}-1$ & $2\left(C_{3}+C_{1}\right)-3$ & $2\left(C_{2}+C_{1}\right)-3$ \\
\hline$I\left(d_{1} f_{1} \mid R_{e, f}\right)$ & 2 & $2 C_{3}-1$ & $2\left(C_{3}+C_{1}\right)-5$ & $2\left(C_{1}+C_{2}\right)-7$ \\
\hline$I\left(a_{2 C_{3}-1} b_{1} \mid R_{e, f}\right)$ & $2\left(C_{3}-1\right)$ & 0 & $2\left(C_{1}-1\right)$ & $2\left(C_{1}+C_{2}+C_{3}-4\right)$ \\
\hline$I\left(d_{2 C_{3}-3} e_{1} \mid R_{e, f}\right)$ & $2\left(C_{3}-1\right)$ & 2 & $2\left(C_{1}-1\right)$ & $2\left(C_{1}+C_{2}+C_{3}-5\right)$ \\
\hline$I\left(b_{2 C_{1}-1} a_{2 C_{3}-1}^{\prime} \mid R_{e, f}\right)$ & $2\left(C_{3}+C_{1}\right)-3$ & $2\left(C_{1}-1\right)$ & 0 & $2\left(C_{2}+C_{3}-2\right)$ \\
\hline$I\left(c_{2 C_{1}-3} d_{2 C_{3}-3}^{\prime} \mid R_{e, f}\right)$ & $2\left(C_{3}+C_{1}\right)-5$ & $2\left(C_{1}-1\right)$ & 2 & $2\left(C_{2}+C_{3}-3\right)$ \\
\hline$I\left(d_{1}^{\prime} f_{1}^{\prime} \mid R_{e, f}\right)$ & $2\left(C_{3}+C_{1}-2\right)$ & $2\left(C_{1}-1\right)$ & 3 & $2 C_{2}-3$ \\
\hline$I\left(a_{1}^{\prime} c_{1}^{\prime} \mid R_{e, f}\right)$ & $2\left(2 C_{3}+C_{1}-3\right)$ & $2\left(C_{1}+C_{3}\right)-3$ & $2 C_{3}-1$ & $2 C_{2}-1$ \\
\hline$I\left(e_{2 C_{1}-3}^{\prime} f_{2 C_{2}-3}^{\prime} \mid R_{e, f}\right)$ & $2\left(C_{2}+C_{1}-2\right)$ & $2\left(C_{1}+C_{3}+C_{2}-3\right)$ & $2\left(C_{3}+C_{2}-2\right)$ & 0 \\
\hline$I\left(b_{2 C_{1}-1}^{\prime} c_{2 C_{2}-1}^{\prime} \mid R_{e, f}\right)$ & $2\left(C_{2}+C_{1}-1\right)$ & $2\left(C_{1}+C_{3}+C_{2}\right)-5$ & $2\left(C_{3}+C_{2}-1\right)$ & 2 \\
\hline$I\left(c_{2 C_{2}-1} b_{1}^{\prime} \mid R_{e, f}\right)$ & $2 C_{3}-1$ & $2\left(C_{3}+C_{2}-1\right)$ & $2\left(C_{3}+C_{2}+C_{1}\right)-5$ & $2\left(C_{1}-1\right)$ \\
\hline$I\left(f_{2 C_{2}-3} e_{1}^{\prime} \mid R_{e, f}\right)$ & $2 C_{2}-1$ & $2\left(C_{3}+C_{2}-2\right)$ & $2\left(C_{3}+C_{2}+C_{1}\right)-7$ & $2\left(C_{1}-2\right)$ \\
\hline
\end{tabular}




\section{Conclusions}

The idea of studying chemical structures using graph theory terminologies is appealing and advantageous. It facilitates chemical researchers' exploration of various chemical networks and topologies in a more systematic and accessible manner. We estimated the edge metric and fault-tolerant edge metric dimension of a hollow coronoid topology with six sides. The above parameters are constant and independent of the hollow coronoid vertices, as shown.

Author Contributions: A.N.A.K. contributed towards conceptualization, data curation, funding acquisition, project administration, and resources. A.A. contributed towards investigation, methodology, conceptualization, supervision, and validation. M.I. contributed towards investigation, methodology, resources, and validation. M.A. contributed towards investigation, methodology, conceptualization, and validation. All authors read and approved the initial and final version of the paper. All authors have read and agreed to the published version of the manuscript.

Funding: There is no funding associated with this manuscript.

Institutional Review Board Statement: Not applicable.

Informed Consent Statement: Not applicable.

Data Availability Statement: Not applicable.

Conflicts of Interest: The authors declare no conflicts of interest.

\section{References}

1. Joita, D.-M.; Jäntschi, L. Extending the characteristic polynomial for characterization of $C_{2} 0$ Fullerene Congeners. Mathematics 2017, 5, 84. [CrossRef]

2. Slater, P.J. Leaves of trees, Proceeding of the 6th Southeastern Conference on Combinatorics, Graph Theory, and Computing. Congr. Numer. 1975, 14, 549-559.

3. Harary, F.; Melter, R.A. On the metric dimension of a graph. ARS Comb. 1976, 2, 191-195.

4. Cáceres, J.; Hernando, C.; Mora, M.; Pelayo, I.M.; Puertas, M.L.; Seara, C.; Wood, D.R. On the metric dimension of cartesian products of graphs. SIAM J. Discret. Math. 2007, 21, 423-441. [CrossRef]

5. Chartrand, G.; Salehi, E.; Zhang, P. The partition dimension of a graph. Aequ. Math. 2000, 59, 45-54. [CrossRef]

6. Hauptmann, M.; Schmied, R.; Viehmann, C. Approximation complexity of metric dimension problem. J. Discret. Algorithms 2012, 14, 214-222. [CrossRef]

7. Lewis, H.R.; Garey, M.R.; Johnson, D.S. Computers and intractability. A guide to the theory of NP-completeness. J. Symb. Log. 1983, 48, 498-500. [CrossRef]

8. Chartrand, G.; Eroh, L.; Johnson, M.A.; Oellermann, O.R. Resolvability in graphs and the metric dimension of a graph. Discret. Appl. Math. 2000, 105, 99-113. [CrossRef]

9. Sebő, A.; Tannier, E. On metric generators of graphs. Math. Oper. Res. 2004, 29, 383-393. [CrossRef]

10. Khuller, S.; Raghavachari, B.; Rosenfeld, A. Landmarks in graphs. Discret. Appl. Math. 1996, 70, 217-229. [CrossRef]

11. Söderberg, S.; Shapiro, H.S. A combinatory detection problem. Am. Math. Mon. 1963, 70, 1066-1070. [CrossRef]

12. Manuel, P.; Bharati, R.; Rajasingh, I. On minimum metric dimension of honeycomb networks. J. Discret. Algorithms 2008, 6, 20-27. [CrossRef]

13. Perc, M.; Gómez-Gardenes, J.; Szolnoki, A.; Floría, L.M.; Moreno, Y. Evolutionary dynamics of group interactions on structured populations: A review. J. R. Soc. Interface 2013, 10, 20120997. [CrossRef]

14. Perc, M.; Szolnoki, A. Coevolutionary games-A mini review. BioSystems 2010, 99, 109-125. [CrossRef]

15. Johnson, M. Structure-activity maps for visualizing the graph variables arising in drug design. J. Biopharm. Stat. 1993, 3, 203-236. [CrossRef]

16. Johnson, M. Browsable structure-activity datasets. Adv. Mol. Similarity 1998, 2, 153-170.

17. Melter, R.A.; Tomescu, I. Metric bases in digital geometry. Comput. Vis. Graph. Image Process. 1984, 25, 113-121. [CrossRef]

18. Imran, S.; Siddiqui, M.K.; Imran, M.; Hussain, M. Computing the Upper Bounds for the Metric Dimension of Cellulose Network. Appl. Math. E Notes 2019, 19, 585-605.

19. Siddiqui, H.M.A.; Imran, M. Computing the metric and partition dimension of H-Naphtalenic and VC5C7 nanotubes. J. Optoelectron. Adv. Mater. 2015, 17, 790-794.

20. Hussain, Z.; Munir, M.; Chaudhary, M.; Kang, S.M. Computing metric dimension and metric basis of 2D lattice of alpha-boron nanotubes. Symmetry 2018, 10, 300. [CrossRef]

21. Simonraj, F.; George, A. On the metric Dimension of silicate stars. ARPN J. Eng. Appl. Sci. 2015, 10, $2187-2192$. 
22. Koam, A.N.; Ahmad, A. Barycentric subdivision of Cayley graphs with constant edge metric dimension. IEEE Access 2020, 8 , 80624-80628. [CrossRef]

23. Zhang, Y.; Gao, S. On the edge metric dimension of convex polytopes and its related graphs. J. Comb. Optim. 2020, 39, 334-350. [CrossRef]

24. Ahsan, M.; Zahid, Z.; Zafar, S.; Rafiq, A.; Sindhu, M.; Umar, M. Computing the edge metric dimension of convex polytopes related graphs. J. Math. Comput. Sci. 2021, 22, 174-188. [CrossRef]

25. Yang, B.; Rafiullah, M.; Siddiqui, H.M.A.; Ahmad, S. On Resolvability parameters of some wheel-related graphs. J. Chem. 2019, 2019, 9259032. [CrossRef]

26. Raza, Z.; Bataineh, M.S. The comparative analysis of metric and edge metric dimension of some subdivisions of the wheel graph. Asian Eur. J. Math. 2020, 14, 2150062 . [CrossRef]

27. Yero, I.G. Vertices, edges, distances and metric dimension in graphs. Electron. Notes Discret. Math. 2016, 55, 191-194. [CrossRef]

28. Azeem, M.; Nadeem, M.F. Metric-based resolvability of polycyclic aromatic hydrocarbons. Eur. Phys. J. Plus 2021, 136, 1-14. [CrossRef]

29. Zhang, R.; Yang, B.; Shao, Z.; Yang, D.; Ming, P.; Li, B.; Ji, H.; Zhang, C. Graph theory model and mechanism analysis of carbon fiber paper conductivity in fuel cell based on physical structure. J. Power Sources 2021, 491, 229546. [CrossRef]

30. Nadeem, M.F.; Azeem, M.; Khalil, A. The locating number of hexagonal Möbius ladder network. J. Appl. Math. Comput. 2021, 66, 149-165. [CrossRef]

31. Koam, A.; Ahmad, A.; Abdelhag, M.E.; Azeem, M. Metric and Fault-Tolerant Metric Dimension of Hollow Coronoid. IEEE Access 2021, 9, 81527-81534. [CrossRef]

32. Kelenc, A.; Tratnik, N.; Yero, I.G. Uniquely identifying the edges of a graph: The edge metric dimension. Discret. Appl. Math. 2018, 251, 204-220. [CrossRef]

33. Liu, X.; Ahsan, M.; Zahid, Z.; Ren, S. Fault-tolerant edge metric dimension of certain families of graphs. AIMS Math. 2021, 6, 1140-1152. [CrossRef]

34. Brunvoll, J.; Cyvin, B.N.; Cyvin, S.J. Enumeration and classification of coronoid hydrocarbons. J. Chem. Inf. Comput. Sci. 1987, 27, 14-21. [CrossRef]

35. Cyvin, S.J.; Brunvoll, J.; Cyvin, B.N. Lecture Notes in Chemistry: Theory of Coronoid Hydrocarbons; Springer: Berlin/Heidelberg, Germany, 1991.

36. Shabbir, A.; Azeem, M. On the Partition Dimension of Tri-Hexagonal $\alpha$-Boron Nanotube. IEEE Access 2021, 9, $55644-55653$. [CrossRef]

37. Cyvin, S.J.; Brunvoll, J.; Chen, R.S.; Cyvin, B.N.; Zhang, F.J. Lecture Notes in Chemistry: Theory of Coronoid Hydrocarbons II; Springer: Berlin/Heidelberg, Germany, 1994.

38. Sarkar, P.; Pal, A.; De, N. The (a,b)-Zagreb index of line graphs of subdivision graphs of some molecular structures. Int. J. Math. Ind. 2020, 12, 2050006. [CrossRef]

39. Gao, W.; Jamil, M.K.; Javed, A.; Farahani, M.R.; Imran, M. Inverse sum indeg index of the line graphs of subdivision graphs of some chemical structures. UPB Sci. Bull. Ser. B 2018, 80, 97-104.

40. Cyvin, S.J.; Brunvoll, J.; Cyvin, B.N. Topological aspects of benzenoid and coronoids, including snowflakes and laceflowers. Comput. Math. Appl. 1989, 17, 355-374. [CrossRef]

41. Afzal, F.; Hussain, S.; Afzal, D.; Hameed, S. M-polynomial and topological indices of zigzag edge coronoid fused by starphene. Open Chem. 2020, 18, 1362-1369. [CrossRef]

42. Dias, J.R. The polyhex/polypent topological paradigm: Regularities in the isomer numbers and topological properties of select subclasses of benzenoid hydrocarbons and related systems. Chem. Soc. Rev. 2010, 39, 1913-1924. [CrossRef] [PubMed] 